\title{
EL AGUA Y EL ETERNO FEMENINO: ESTUDIO DE CIRCE Y EL POETA MANUEL CIGES APARICIO SEGÚN LAS TEORÍAS DE GASTON BACHELARD
}

\author{
WATER AND FEMALENESS: STUDY ABOUT CIRCE AND THE POET MANUEL \\ CIGES APARICIO ACCORDING TO GASTON BACHELAR'S THEORIES
}

María Ignacia Barraza

Simon Fraser University, Canadá

\section{RESUMEN:}

La novela Circe y el poeta, escrita por el español Manuel Ciges Aparicio y publicada en 1926, es, como sugiere el título, una reinterpretación del mito de la hechicera griega. Efectivamente, Sara -el personaje femenino con mayor relieve en el relato-, es una moderna seductora a la manera de la Circe (1927) del pintor alemán George Grosz. Este ensayo pretende demostrar -apoyándose en las teorías de Gaston Bachelard acerca de la imaginación material del agua- cómo Ciges Aparicio utiliza dicho elemento como símbolo de lo femenino, del dolor y de la muerte.

\section{Palabras claves:}

Manuel Ciges Aparicio, Eterno Femenino, Gaston Bachelard, Circe y el poeta.

\section{Abstract:}

The novel Circe and the poet, written by Manuel Ciges Aparicio and published in 1926, is, as its title suggests, a reinterpretation of the classic myth. In fact, Sara -the main female character in the story- is presented as a modern seductress that has a lot in common with German painter George Grosz's Circe (1927). This essay aims to show how Ciges Aparicio uses water -the female element par excellence- as a literary symbol that underlines themes such as pain, death and suffering. For our purpose, we will rely on French philosopher Gaston Bachelard's theories as expounded in his work Water and Dreams (1942).

\section{KEY WORD:}

Manuel Ciges Aparicio, Femaleness, Gaston Bachelard, Circe and the poet. 
Manuel Ciges Aparicio (1873-1936), autor español poco conocido dentro de los cánones de la literatura de posguerra, tuvo, irónicamente, cierta notoriedad en vida. Efectivamente, desde la publicación de su primer libro, El libro de la vida trágica. Del Cautiverio (1903), nuestro autor se granjeó el favor tanto del público como el de los críticos, como testimoniaba Rafael Cansinos Assens, que en su día alababa sus "valores literarios, [los cuales] conferíanle paridad con los grandes nombres nacientes del momento" (Cansinos Assens 1927: 170). El corpus narrativo cigeano consta de algunas novelas combativas y de otras (como su primera novela, El Vicario, 1905), donde hace uso de una prosa que recuerda vagamente el preciosismo del lenguaje de la Sonata de otoño valleinclanesca. El resto de las obras salidas de la pluma de Ciges Aparicio están repartidas entre libros autobiográficos (los llamados Cuatro Libros), reportajes novelescos (Los vencedores y Los vencidos), obras que versan sobre historia (España bajo la dinastía de los Borbones), y una biografía sobre Joaquín Costa (Joaquín Costa, el gran fracasado).

En este ensayo, nos proponemos estudiar una de las últimas novelas largas que nuestro autor publicó, Circe y el poeta. Publicada en 1926 y ambientada en el París prebélico, esta novela representa una vaga interpretación del mito de la hechicera griega, convertida ésta en moderna seductora, a la manera de la Circe del pintor alemán George Grosz (1893-1959). Más específicamente, nos proponemos estudiar detenidamente el simbolismo del agua del que se sirve nuestro autor en esta novela; simbolismo que puede arrojar luz sobre la concepción (consciente e inconsciente) de lo femenino, propio de la época de Ciges Aparicio.

No está de más añadir aquí que el protagonista de Circe y el poeta, el poeta español Adolfo Lena, se emparenta con los personajes fracasados de las mejores novelas de los noventayochistas (pensemos en La voluntad de Azorín o Camino de perfección de Pío Baroja, por ejemplo), ya que su voluntad se quiebra ante la presencia de la mujer, que al final lo subyuga ${ }^{1}$. Lena es derrotado sentimentalmente por una mujer que posee unas características (obstinación, energía física, inteligencia) que lo seducen y a la vez lo inquietan.

Comencemos, pues, con un estudio del tema recurrente del agua en esta obra, ya que éste nos lleva a pensar que Ciges la utiliza como leitmotiv a lo largo de la misma. Podemos decir, a grandes rasgos, que el uso del agua como tema literario, aquí sirve para acrecentar el sentimiento de opresión que subyace en todo el relato. El melancólico cielo pardo parisino adquiere tonos agobiantes; la humedad llega a penetrar en los

1 Como acertadamente señala Cansinos Assens, Sara, “[...] enredándole en la cambiante urdimbre de sus locuras y caprichos, protegiéndole con denigrante prodigalidad y arrastrándole por bailes y cabarets le hace perder [a Lena] el gusto al trabajo honrado y acelera al propio tiempo su proceso morboso, causando [la] ruina física y moral [del vate]". Vid. Cansinos Assens, Rafael, La nueva literatura..., tomo IV, op. cit., p. 181 huesos del lector. No obstante, es menester matizar estas observaciones, y para ello nos serviremos principalmente de las ideas acerca de la imaginación material del agua postuladas por el filósofo francés Gaston Bachelard (1884-1962) en su conocido libro, El agua y los sueños (1942), además del clásico Diccionario de símbolos de Juan Eduardo Cirlot (1916-1973).

Bachelard resalta la diferencia entre lo que él llama la imaginación formal y la imaginación material. Es esta última la que interesa al filósofo; efectivamente, a lo largo de su estudio, intenta comprobar que existen "imágenes directas de la materia" (Bachelard 2005: 2). Existe, de esta manera, una poética del agua; "ese líquido universal" (Bachelard 2005: 84) produce imágenes profundas -situadas en las antípodas de las imágenes librescas utilizadas por poetas mediocres- que forman parte de lo que podríamos llamar el inconsciente colectivo jungeano ${ }^{2}$

La materia debe informar o alimentar una imagen para que ésta sea válida estéticamente; en el caso contrario, como señala Bachelard, "[m]uchas imágenes intentadas no pueden vivir porque son simples juegos formales, porque no están verdaderamente adaptadas a la materia que deben adornar" (Bachelard 2005: 11). En fin, las imágenes poéticas "tienen una materia", según el filósofo francés (Bachelard 2005: 11) y cada uno de los cuatro elementos es capaz de evocar imágenes que son propias a su "sistema de fidelidad poética" (Bachelard 2005: 14).

Podemos decir que en la novela Circe y el poeta, el agua -en todas sus manifestacionesno es mero adorno del paisaje literario; el agua es, por el contrario, la sustancia que engendra esas ensoñaciones bachelardianas ligadas al inconsciente. Como comprobaremos, el elemento hídrico en esta obra acoge imágenes ligadas a la muerte y al sufrimiento; así, desde las primeras escenas de la novela nos enfrentamos a un sentimiento de opresión y dolor, ligado a lo húmedoํ․ Por ejemplo, en el prime

2 Bachelard parece definir a la perfección dicho concepto jungeano cuando, al referirse a los cuatro elementos, escribe: "[a]l cantarlos creemos ser fieles a una imagen favorita, y en realidad somos fieles a un sentimiento humano primitivo, a una realidad orgánica primera, a un temperamento onírico fundamental". Vid. El agua y los sueños, op. cit., p. 14

3 Ya en su primer libro (El libro de la vida trágica. Del cautiverio, 1903) comprobamos que el agua juega un papel determinante en las ensoñaciones del narrador-protagonista, en una página que podría haber sido arrancada de la obra de Edgar Allan Poe (1809-1849). Véase, sino, la siguiente escena, donde el agua marina se asocia íntimamente a la muerte, creando una visión dantesca: "[f ue en [la ciudad cubana de] Mariel donde visité la mansión de los reconcentrados. Al lado de una playa sucia, de aguas lívidas e inmóviles que exhalaban miasmas homicidas, alzábanse los sórdidos barrancones de tostadas palmeras. Reinaba silencio de cementerio: ni una voz, ni un gemido. El mar dormía hipnotizado bajo los inmensos haces ígneos que el sol del mediodía le enviaba. De la tersa superficie opalina brotaban vivísimas refracciones, áureo chisporroteo de hirviente metal que hería los ojos y aumentaba el cansancio del espíritu. Cuando llegué a este paraje de pesadilla y maldición me detuve para escuchar. ¡Ni un rumor del mar, ni un suspiro de los hombres! Sólo barrunté en la cara el tácito pasar de un vaho caliginoso y repugnante. Era la muerte, callada e invisible soberana de la vasta necrópolis, que me azotaba desdeñosa el rostro". Vid. Ciges Aparicio, Manuel, El libro de la vida trágica..., op. cit., p. 127. 
capítulo, al escapar del calabozo, Lena comienza a correr hasta "no dar más de sí mismo", y al detenerse para ubicarse en pleno campo, siente frío, ya que "[l]a camisa y el traje de mecánica estaban empapados de sudor y se le adherían al cuerpo" (Ciges Aparicio 2003: 18)

De la misma manera, es significativo el hecho de que es la humedad -unida al frío, en este caso- la que desata la violenta tos que lo seguirá y fustigará a lo largo del relato; es el primer ataque que presagia su trágica muerte al final del relato debido a la tisis. El desventurado poeta prosigue su camino hacia la libertad, pero “[h]acia la mitad de la marcha le atacó la tos seca y tenaz que por primera vez sintió una noche bajo los puentes de Turia, allá en Valencia, buscado por la policía en víspera de su primera emigración" (Ciges Aparicio 2003: 18)

Más adelante, una vez llegado a París, el agua se convierte en una suerte de arma letal, ya que el vate español se encuentra con una "[...] llovizna helada [que] sintió en el rostro como puntas de cristales" (Ciges Aparicio 2003: 24). La lluvia será, en efecto, el primer obstáculo para Lena, que se encuentra en París sin paraguas y sin dinero, y se ve forzado, por tanto, a continuar su camino a pie hasta llegar a la casa de un conocido ex-revolucionario: “[e]n el [boulevard] de Poissonnière recomenzó a llover más fuerte. En el de San Martín tuvo que detenerse empapado. Todo era humedad abajo, agua en el aire, hielo en su sangre; pero sus pómulos ardían y la tos seca le apretaba la garganta" (Ciges Aparicio 2003: 25-26)ํ․ La lluvia fustigará sin piedad al malogrado vate, obstaculizando su visión: "[...] el chispeo se convirtió en lluvia y, al llegar a [la plaza], el agua caía a grandes duchas, inundándole el rostro e impidiéndole ver" (Ciges Aparicio 2003: 38).

La visión del agua como elemento amenazador o destructor también se manifiesta en el hecho de que el Sena se ofrece como una tentación al suicidio cuando el protagonista se siente abatido. Dicha inclinación a la sustancia líquida aniquiladora no debe extrañar, ya que, como señala Bachelard, “[e]l agua es también una invitación a morir: es una invitación a una muerte especial que nos permite alcanzar uno de los refugios materiales elementales" (Bachelard 2005: 78)

4 Otra vez, el narrador insiste en la connotación negativa del agua, ya que se asocia la tos sofocadora y el recuerdo amargo del primer exilio al puente del río Turia, insistiendo el narrador en el hecho de que fue cerca del agua donde Lena sintió por primera vez la tos que anunciará su muerte.

5 Más adelante en la narración, el jefe de la Editorial Iberoamericana, Daniel Hervás, le pregunta si se siente enfermo, a lo cual Lena responde, "[e]s la humedad... He recibido tanta agua desde ayer...". Vid. Circe y el poeta, op. cit., p. 44.

6 Aquí no podemos evitar mencionar la célebre novela de Miguel de Unamuno, San Manuel Bueno, mártir (1930) y, más específicamente, una escena donde el agua del lago representa esa "invitación a morir": " $\mathrm{i} Y$ cómo me llama esa agua con su aparente quietud -supuestamente confiesa el sacerdote al hermano de Ángela- [...] ¡Mi vida, Lázaro, es una especie de suicidio continuo, un combate contra el suicidio, que es igual [...]". Vid. Unamuno, Miguel de, San Manuel Bueno, mártir, op. cit., p. 147.
Las alusiones al suicidio son múltiples: "[a]l cruzar el Sena detúvose un momento sintiendo la mortal fascinación que su verde corriente ejerce sobre los desesperados [...]" (Ciges Aparicio 2003: 25). Más adelante, cuando un panadero le niega una rodaja de pan al pagarle Lena con un falso franco, éste "[...] entrevió el río de las verdes aguas cautivadoras; pero aquel blando lecho estaba muy lejos" (Ciges Aparicio 2003: 36) En otra escena, cuando el poeta español se dirige hacia la Editorial Iberoamericana, considera la posibilidad de arrojarse a las aguas del Sena si no le entregan alguna traducción para subsistir. Él mismo reflexiona de manera casi jocosa: “¿[e]n cuál de sus brazos líquidos le recibiría el río, si dentro de algunos minutos le reservaban una acogida adversa?"(Ciges Aparicio 2003: 39)ํ․ En fin, las aguas del Sena, seductoras como las formas femeninas, lo atraen por un tiempo, como el canto de las sirenas: cuando el jefe de la editorial le ofrece traducir una obra de Terencio, éste recuerda de que las casas editoriales no suelen pagar hasta que se entrega el trabajo finalizado, por tanto, decide en ese momento que "[...] sus cuentas estaban echadas: se arrojaría al río con Terencio" (Ciges Aparicio 2003: 45). Una vez que su suerte mejora, el vate intenta no contemplar las aguas verdes y atrayentes del Sena, que le alargan los brazos casi maternales para ahogarlo en su seno: “[p]ensando en la Señora Luna descendió por el bulevar Saint-Michel, cruzó el puente sin querer mirar las aguas verdes del Sena y se fue a la Samaritana [...] Desanduvo el camino; corazón rencoroso, ni siquiera se dignó de mirar al río [...]" (Ciges Aparicio 2003: 47).

Un Sena simbólico vuelve a amenazar con inundar la capital, en una escena que se desarrolla durante la Nochevieja. Así Lena, en tono festivo, declara que

\section{[u]n Sena de champaña empieza a desbordarse por París, y es natural que el barrio también se anegue. Entre tanto náufrago, es probable que alguno bracee buscando la tabla de salvación y se agarre a ustedes [las amigas de Sara: Alicia y Julia]. Ninguna autoridad podrá evitar, y yo me pondŕa en rid́culo si inhuma julia]. Ninguna autorich sufrirán algún abrazo, siempre seguido de un beso (Ciges Aparicio 2003: 108).}

Si bien el Sena parece representar para el malogrado vate una vía de escape a su realidad vital, el mar abierto le causa una terrible sensación de ahogo y de malestar físico y psíquico. Ahora bien, es lícito preguntarnos: ¿Cuál es la causa de esta sensación negativa en nuestro protagonista? Una inferencia apresurada nos llevaría a pensar que Ciges se sirve aquí de un simbolismo superficial; Lena sentiría así un malestar físico y psíquico debido a que el mar,

$7 \mathrm{La}$ asociación que se establece entre el agua y el elemento femenino aquí nos parece interesante, ya que la imagen del cuerpo de agua que le extiende los brazos no puede ser sino la imagen de la madre que invita al hijo a volver al calor y seguridad de la cavidad uterina, lugar donde ya nada puede hacerle daño. 
[en] su sentido simbólico corresponde al del 'océano inferior', al de las aguas en movimiento, agente transitivo y mediador entre lo no formal (aire, gases) y lo formal (tierra, sólido) y, analógicamente, entre la vida y la muerte. El mar, los océanos, se consideran así como la fuente de la vida y el final de la misma. 'Volver al mar' es como 'retornar a la madre', morir (Cirlot 1997: 305).

No obstante, cabe destacar aquí que no solamente el mar ha sido considerado a lo largo de la Historia esa "fuente de la vida y el final de la misma": todas las masas de agua tienen las mismas connotaciones simbólicas. Como señala Bachelard, el agua en general puede mezclar sus "símbolos ambivalentes de nacimiento y de muerte" (Bachelard 2005: 121). Como hemos dicho más arriba, el agua en esta novela se asocia a la muerte y, por consiguiente, a lo maternal, a lo femenino. Mientras el Sena le alarga sus maternales brazos líquidos para ahogarlo, el mar tiene un efecto físico y real sobre el poeta: "[a] veces se le apretaba el pecho como si le faltase aire, y estas sofocaciones las atribuía a la proximidad del mar" (Ciges Aparicio 2003: 170). Más adelante,

[a] medida que se acercaban al Canal de la Mancha, Lena recibía en su pecho la influencia oceánica. Respiraba con dificultad. El avance por los húmedos campos célticos, en que se densificaban las nieblas, le inundaba de tristeza. Sentía gran sopor y una disminución de energías físicas y espirituales (Ciges Aparicio 2003: 202)

Ese terror que le inspira el agua marina, asimismo, se hace patente una mañana durante su estancia con Sara en las costas bretonas, cuando "[a]l amanecer, comenzó el retorno del mar y el ruido de su invasión le infundía inexplicables terrores. Hacia las ocho salió a la terraza. Las aguas cubrían las arenas batiendo la costa de Avranches. Viéndole pálido, Sara propuso suspender el viaje [...]" (Ciges Aparicio 2003: 203)ํ․

El mar, como vemos, se convierte en un ente amenazante, que lo afecta a nivel inconsciente, y cuya nefasta influencia se manifiesta en síntomas somáticos. Merece la pena detenernos aquí para demostrar que el miedo irracional que Lena siente al encontrarse cerca del agua se debe a las ensoñaciones luctuosas que le inspira el elemento líquido. Efectivamente, si tenemos en cuenta el hecho de que la imaginación material del río Rance recrea el simbolismo de Caronte en las páginas de la novela que nos ocupa, entonces comenzamos a comprender la aprensión de Lena hacia toda masa de agua. Las siguientes palabras escritas por Bachelard a propósito de lo que él denominó complejo de Caronte nos parecen esclarecedoras al respecto: “[...] la función de un simple barquero, desde que aparece ubicada en una obra literaria, queda fatalmente tocada

8 Hay que señalar a estas alturas que los efectos negativos del agua y de la humedad sobre el poeta no se deben simplemente a la tisis de la que padece, sino que tiene además un efecto sobre su espíritu, ya que lo llenan de una tristeza insondable.

9 Comprobamos una vez más que el agua tiene un efecto directo sobre su espíritu; en este caso, le infunde "inexplicables" terrores. por el simbolismo de Caronte. Aunque haga el simple cruce de un simple arroyo, contiene el símbolo del más allá. El barquero es el guardián de un misterio" (Bachelard 2005: 106).

Valorada a la luz de estas palabras reveladoras, la escena que se desarrolla en el capítulo XXI -en un barco que transporta a Lena sobre las aguas del Rance hacia la casa de Sara-Circe (que el poeta asocia directamente a la muerte)- cobra una dimensión más profunda, que se tiñe asimismo de tonos sombríos: "[c]uando llegaron al barco, la cubierta estaba llena de excursionistas. Muchos llevaban libros, álbumes y aparatos fotográficos [...] El barco desatracó sin ruido y fue avanzando suavemente hacia la puerta terrestre. Luego prosiguió su marcha entre las dos márgenes de esmeralda empujado por la marea [...]" (Ciges Aparicio 2003: 205).

No es de extrañar, por consiguiente, que al encontrarse flotando sobre estas aguas funestas, los pensamientos de Lena estén dirigidos al Último Viaje: “[l]a muerte se le identificó con el sueño, y el sopor que le inundaba era como una disminución de vida y un avance sigiloso hacia la quietud inalterable" (Ciges Aparicio 2003: 206); "Lena comprendió que sólo para morir podría vivir en la casa de Sara" (Ciges Aparicio 2003: 207). Comprobamos que el agua -en cuanto elemento material (y maternal)- es un factor determinante en las ensoñaciones luctuosas del vate.

Nos interesa aquí detenernos en otra curiosa escena que se desarrolla en el capítulo XXI y que arroja luz acerca de esas ensoñaciones bachelardianas. Lena, una vez que se encuentra en San Malo, se detiene para contemplar la tumba del escritor francés Chateaubriand que, como se sabe, se encuentra cercana al mar. De repente, el vate comienza a sentir un terror inexplicable al observar que "[e]l mar cubría la tumba, y en su lenta retirada iba surgiendo la cruz. Luego empezó a descubrirse la losa marmórea. El poeta pensó en el cuerpo tendido y fue víctima de una alucinación, viéndose él mismo preso en la cavidad e inundado de agua amarga... ¡Se ahogaba!" (Ciges Aparicio 2003: 204) $)^{10}$.

Es evidente aquí la identificación del agua con el sentirse ahogado, que podemos interpretar como presagio de la muerte próxima de Lena, que volverá a la nada. Además, en términos psicoanalíticos, este terror al agua se podría interpretar como

10 Podemos interpretar asimismo la reacción de espanto de Lena frente a dicha cavidad como la "reacción masculina ante la visión fisural y de hueco del sexo femenino" que desde tiempos inmemoriales produce vértigo y rechazo en el hombre. Vid. Vilarós, Teresa M., Galdós: invención de la mujer y poética de la sexualidad..., op. cit., p. 10. Asimismo, nos parece muy interesante aquí citar las palabras de Ramón Gómez de la Serna, que asocia explícitamente la mujer al agua, reviviendo el mito del nacimiento de Venus: “[l]a mujer es una cosa lagunícea, una última ocultación de la espuma o saliva del mar, algo así que despierta el deseo hipertenaz de encontrar la escondida rana del placer. Cumplido su oleaje ha cumplido esa llamada a uno mismo que hay en su contacto y que no se puede encontrar por otro camino, pues sólo está en ese pozo que atrae y ahoga y en cuya profundidad se repite su forma como si estuviese enterrada en serie su propia estatua". Vid. Gómez de la Serna, Ramón, Automoribundia (1888-1948), op. cit., p. 428 
aprensión hacia lo femenino, como venimos diciendo, ya que el agua nos remite al útero y, más específicamente a la bolsa uterina, que actúa como un aislante físico, pero también simbólico, ya que representa un estado de inconsciencia, una suerte de limbo de la existencia humana. Podemos afirmar, de esta manera, que en esta obra se funde y se confunde el elemento femenino con el agua ${ }^{11}$. No sorprende, por ende, que el poeta “[vuelva] a horrorizarse pensando en la tumba de Chateaubriand. Él no deseaba sentir la conciencia póstuma de contemplar el Océano [sic] desde una costa, ni que las olas rodasen sobre su sepulcro [...]" (Ciges Aparicio 2003: 206)

No obstante, si nos atenemos a las ideas postuladas por Bachelard, notamos que no es solamente la asociación del elemento líquido a lo femenino lo que aterra al protagonista cigeano. Si tenemos en cuenta que la primera imagen que salta a la mente del poeta es aquella del escritor francés "tendido", "preso" en la losa marmórea, entonces entendemos que no es la muerte misma la que horroriza a Lena, sino más bien el hecho de que el autor romántico no pueda realizar el viaje hacia el más allá, ya que se encuentra atrapado en una caja de mármol que le impide disolverse en la sustancia marina y primordial. Chateaubriand, en el subconsciente de Lena, estaría, así, dormido, preso en las “aguas amargas" (Ciges Aparicio 2003: 204), ya que como señala Bachelard, "[d]espués de los funerales [los muertos] son, para el inconsciente, ausentes, es decir, durmientes más escondidos, más encubiertos, más adormecidos" (Bachelard 2005: 89). Lena, por el contrario, “[...] no deseaba sentir la conciencia póstuma de contemplar el Océano [sic] desde una costa, ni que las olas rodasen sobre su sepulcro [...] Morir en estos prados nemorosos donde seres y cosas perdían su individualidad se le antojaba disolverse en ellos y vivir en todo sin la angustia de fallecer" (Ciges Aparicio 2003: 206).

El poeta español, de esta manera, rechaza una muerte a medias -Chateaubriand es, al fin y al cabo, un muerto durmiente-, prefiriendo el tipo de muerte que desearía para sí: una muerte total, que podríamos describir con las siguientes palabras de Bachelard: "[d]esaparecer en el agua profunda o desaparecer en un horizonte lejano, asociarse a la profundidad o a la infinitud; tal es el destino humano que busca su imagen en el destino de las aguas" (Bachelard 2005: 24)

Por último, espiguemos dos ejemplos más, donde el agua aparece como signo fatal En el capítulo VI, Lena, ebrio y enfermo, se dirige en automóvil hacia el hotel donde está alojado, después de haber visitado una cueva de apaches con Sara, y siente que oscila “[...] entre el letargo y la vigilia, [y] figurábase luchar con desesperación y denuedo en

11 Como señala Juan Eduardo Cirlot, la asociación del agua al elemento femenino se remonta a tiempos inmemoriales: "[e]n los Vedas, las aguas reciben el apelativo de mâtrita-mah (las maternas) pues, al principio, todo era como un mar sin luz. En general, en la India, se considera a este elemento como el mantenedor de la vida que circula a traves de toda la naturaleza en forma de lluvia, savia leche, sangre". Vid. Cirlot, Juan Eduardo, Diccionario de símbolos, op. cit., p. 68. el centro de las aguas que rodaban sobre su cabeza. A veces emergía de ellas, viendo alzarse Nuestra Señora a su izquierda y la Morga detrás" (Ciges Aparicio 2003: 69).

En este pasaje, se asocian los líquidos corrosivos que había ingerido el poeta con las aguas venenosas y tentadoras del Sena, como hemos visto más arriba. Es interesante señalar que el sentimiento de ahogo se agudiza conforme avanza la narración, y la enfermedad del mismo empeora. El sentimiento de ahogo y asfixia se convierte así en ritornelo agobiante, que nos remite a la interpretación negativa del agua como ente amenazador, como encarnación líquida de la madre-muerte, que acecha a nuestro protagonista en cada rincón y a cada instante.

Por último, hay que hacer notar que en otra ocasión, durante una secuencia que se desarrolla a manera de flashback (cap. XV), un joven Lena, junto a un tal Bernabeu, consiguen agitar al pueblo de Valencia, para conseguir que se hiciera huelga ese día como en otras ciudades españolas. Los dos amigos comienzan a hablar a grandes voces, atrayendo a varias personas que se unen a ellos y piden a los comerciantes cerrar sus negocios y unirse a la huelga general. En este caso, Ciges hace uso del tema del agua para referirse a la masa de gente inconsciente que se reúne en torno a los dos jóvenes revolucionarios. Nótese el uso de los vocablos relacionados con el agua para expresar el desbordamiento de la caótica situación:

[e]l río había salido de madre y era imposible evaluar ahora su caudal. Por el mercado avanzaba una corriente confusa y lenta, y sus orillas se confundían con el público movedizo, fluente y denso, que no sabía si pugnaba por empantanarse o por incorporarse al curso central. Era preciso que las aguas populares se encauzasen

[...] (Ciges Aparicio 2003: 150).

Es interesante señalar que aquí también el agua refleja las fuerzas ciegas e impulsivas de las masas populares, las cuales, según el narrador, son fácilmente manipuladas. Una vez más, vemos que el uso de la imagen del agua aquí responde a connotaciones negativas, en cuanto el agua representa lo primigenio, lo instintivo, en oposición diametral a la razón y a la reflexión, facultades éstas que nuestro autor apreciaba sumamente.

\section{REFERENCIAS BibLIOGRÁficAs}

Bachelard, G., El agua y los sueños. Ensayo sobre la imaginación de la materia, México, Fondo de Cultura Económica, 2005.

Cansinos Assens, R., Rafael, La nueva literatura, tomo IV, La evolución de la novela (1917-1927), Madrid, Páez, 1927.

Cirlot, J. E., Diccionario de simbolos, Madrid, Siruela, 1997.

Ciges Aparicio, M., Circe y el poeta, Madrid, Siete Mares, 2003. 
----, El libro de la vida trágica. Del cautiverio, edición de Cecilio Alonso, Alicante, Caja de Ahorros de Alicante y Murcia, Instituto de Estudios Juan Gil-Albert, 1985.

Gómez De La Serna, R., Automoribundia (1888-1948), Buenos Aires, Sudamericana, 1948.

Vilarós, T. M., Galdós: invención de la mujer y poética de la sexualidad. Lectura parcial de Fortunata y Jacinta, Madrid, Siglo XXI de España Editores, 1995.

Unamuno, M., San Manuel Bueno, mártir, edición de Mario Valdés, Madrid, Cátedra, 2003, 24? edición. 